\title{
Pemilihan Platform Tanda Tangan Digital Berdasarkan Faktor Keberlanjutan Selama Pandemi COVID-19 Menggunakan Metode AHP
}

\author{
Ahmad Arif Santosa ${ }^{1}$, Anak Agung Ngurah Perwira Redi ${ }^{2}$ \\ ${ }^{1,2}$ Department of Industrial Engineering, BINUS Graduate Program - Master of Industrial \\ Engineering, Universitas Bina Nusantara, DKI Jakarta, 11530, Indonesia \\ E-mail: ${ }^{1}$ ahmad.santosa@binus.ac.id, ${ }^{2}$ wira.redi@binus.edu
}

\begin{abstract}
Abstrak
Sistem tanda tangan digital telah banyak dimanfaatkan terutama untuk kegiatan persetujuan dokumen selama pandemi COVID-19 di Indonesia. Penelitian ini bertujuan untuk mengetahui faktor-faktor dari dimensi sustainability yang mempengaruhi keberlanjutan dalam menggunakan sistem tanda tangan digital berdasarkan metode pendekatan AHP. Penelitian ini menggunakan metode AHP karena metode ini mampu menyelesaikan persoalan dalam suatu kerangka berpikir yang terorganisir sehingga dapat mengambil keputusan secara efektif dan akurat terhadap suatu persoalan dalam penelitian. Hasil penelitian menunjukkan bahwa subkriteria continuous improvement dari dimensi ekonomi menjadi prioritas utama yang menjadi penunjang dalam keberlanjutan bisnis penyedia tanda tangan digital. Selanjutnya, melakukan analisis pemilihan platform tanda tangan digital antara PrivyID, DigiSign, dan Manual Input. Berdasarkan hasil perhitungan terhadap tiga alternatif menghasilkan platform DigiSign yang paling unggul dibandingkan dengan platform PrivyID dan Manual Input. Hasil tersebut sejalan dengan komitmen dari platform DigiSign yang memberikan kemudahan bagi pengguna agar dapat memeriksa dokumen yang tertunda dengan cepat, menandatangani dokumen dengan tingkat keamanan yang tinggi dan enkripsi berstandar Internasional, serta dapat melacak status dokumen dengan mudah. Sedangkan tanda tangan elektronik yang dilakukan dengan cara Manual Input memiliki kelemahan yang sangat kritikal, dimana tanda tangan elektronik tersebut tidak terenkripsi sehingga tidak mampu untuk melindungi dokumen dari pencurian data identitas atau entitas perusahaan oleh pihak yang tidak bertanggung jawab.
\end{abstract}

Kata kunci: metode AHP, keberlanjutan bisnis, continuous improvement, pencurian data, platform tanda tangan digital

Abstract
The digital signature system has been widely used, especially for document approval activities during the COVID-19 pandemic in Indonesia. This study aims to determine the factors of the sustainability dimension that affect sustainability in using a digital signature system based on the AHP approach. This study uses the AHP method because this method is able to solve problems in an organized framework so that it can take a decisions effectively and accurately on a research problem. The results of this study indicate that the sub-criteria for continuous improvement from the economic dimension is the main priority that supports the sustainability of the digital signature provider business. Furthermore, analyze the selection of digital signature platforms between PrivyID, DigiSign, and Manual Input. Based on the results of the calculation of the three alternatives, the DigiSign platform is the most superior compared to the PrivyID platform and Manual Input. This results are in line with the commitment of the DigiSign platform which makes it easy for users to quickly check pending documents, sign the documents with a high level of security and International standard encryption, and easy to tracking the document status. Meanwhile, electronic signatures made by Manual Input have a very critical weakness, where the electronic signature is not encrypted so it is unable to protect documents from theft of identity data or corporate entities by irresponsible parties.

Keywords: AHP method, business sustainability, continuous improvement, data theft, digital signature platforms 


\section{Pendahuluan}

Di era globalisasi saat ini, persaingan bisnis tidak dapat dihindari. Era globalisasi juga mendorong pertumbuhan ekonomi terutama dengan adanya perkembangan dan penggunaan digitalisasi. Dari kacamata perusahaan dalam teknologi informasi dan komunikasi (ICT), perusahaan pengembang teknologi dapat melihat ini sebagai peluang untuk meningkatkan daya tanggap dalam menanggapi setiap perubahan lingkungan bisnis, kemampuan teknologi, dan permintaan pelanggan ke dalam strategi bisnis. Oleh karena itu, business sustainability dan digitalisasi sangat diperlukan guna menunjang kestabilan bisnis yang dijalankan oleh setiap perusahaan. Keberlanjutan dan digitalisasi adalah dua megatrend yang memainkan peran penting dalam membentuk ekonomi dan aktivitas bisnis perusahaan di tahun-tahun mendatang [1]. Sustainability bertujuan untuk menghadapi tantangan masa depan jangka panjang, hal ini mengacu pada sistem dan proses yang mampu beroperasi dan bertahan sendiri dalam jangka waktu yang lama. Kata sifat "keberlanjutan" berarti "mampu melanjutkan tanpa gangguan" atau "mampu bertahan tanpa gagal". Praktik komprehensif konsep keberlanjutan ini mencakup berbagai proses yang luas dan terus berkembang, membuat bidang ini secara konseptual menjadi membingungkan dan sulit dinavigasi [2].

Selama beberapa dekade terakhir dalam penerimaan dan adopsi teknologi digital semakin meningkat, masyarakat semakin ingin mengadopsi suatu teknologi dalam kehidupan sehari-hari mereka. Perkembangan teknologi dan globalisasi di era dunia modern telah menghasilkan sistem komunikasi yang semakin baik khususnya di bidang digitalisasi dalam teknologi informasi dan komunikasi (ICT) [3]. Pada tahun 2019 hingga 2020, dilaporkan jumlah pengguna internet di Indonesia adalah sebanyak 196,7 juta jiwa atau setara dengan 73,7\% populasi penduduk Indonesia [4]. Meskipun perkembangan ini sangat baik, namun, banyak terjadi kasus-kasus penipuan di dunia IT terkait orisinalitas data, seperti penyebaran email palsu yang melibatkan identitas seseorang. Dengan terjadinya banyak kasus terhadap keamanan data diri seseorang, sehingga penggunaan teknik otentikasi dokumen sangat diperlukan. Penggunaan teknologi yang berkembang di pasaran menjadi hal yang penting untuk meningkatkan industri pemasaran dalam hal pengadopsian tanda tangan digital menjadi kebiasaan baru di masyarakat.

Sejak pemerintah Indonesia mengumumkan pembatasan keramaian akibat pandemi COVID-19, setiap aspek aktivitas masyarakat berubah drastis. Pemerintah melarang keras adanya kegiatan berkumpul di tempat umum bagi masyarakat dengan berbagai upaya seperti: membatasi akses masyarakat dan memberikan sanksi tegas bagi siapa saja yang melanggar. Dengan demikian, proses validasi dokumen tidak dapat dilakukan secara tatap muka di lokasi yang sama akibat pandemi COVID-19 [5], sehingga faktor keberlanjutan sistem tanda tangan digital penting untuk dilakukan analisis lebih mendalam guna menemukan faktor yang paling berpengaruh agar platform tanda tangan digital dapat mencapai sustainability. Oleh karena itu, peneliti merumuskan tujuan dari penelitian ini adalah untuk mengetahui faktor keberlanjutan apa yang menjadi prioritas utama agar penyedia platform tanda tangan digital dapat mencapai sustainability pada setiap platform tanda tangan digital, serta menganalisis pemilihan platform mana yang menjadi favorit bagi masyarakat di era pandemi saat ini. Di sisi lain, penelitian ini bertujuan sebagai landasan dalam melakukan evaluasi bagi setiap penyedia platform tanda tangan digital agar memperhatikan faktor-faktor penting yang menjadi dasar untuk dapat mencapai sustainability pada platform yang dikembangkan. Terutama dalam hal keamanan data pengguna yang merupakan faktor penting yang harus diperhatikan, potensi kejahatan yang biasa terjadi dalam transaksi online seperti penipuan, penyalahgunaan data diri seseorang di dunia maya (carding), hacking, spamming, dan defacing jika sistem keamanan infrastruktur $e$ commerce masih lemah [6]. Indonesia berada di peringkat pertama dalam hal kejahatan dunia maya, sebanyak 40\% kejahatan dunia maya berasal dari Indonesia [7]. Pada tahun 2020, Indonesia menempati peringkat pertama di dunia sebagai negara tujuan serangan siber dengan menerima 495,3 juta serangan siber dari seluruh dunia [4], dimana angka ini meningkat sebesar 41,4\% dibandingkan tahun 2019. Kasus penyebaran konten provokatif, penipuan online, dan pencurian data identitas merupakan kasus yang paling tinggi terjadi di Indonesia. 
Selain faktor serangan siber dari seluruh dunia, digitalisasi sistem pembayaran tingkat nasional di Indonesia mampu mendorong kecepatan transaksi ekonomi secara digital melalui $e$ commerce selama pandemi COVID-19. Dikutip dari Bank Indonesia [8] mencatat bahwa transaksi ekonomi dan pembayaran secara fisik mengalami penurunan sejak awal tahun 2019, dimana sejak tahun 2019 nilai nominal transaksi e-commerce diperkirakan mencapai Rp266,3 triliun atau naik sekitar 29,6\% pada tahun 2020. Hal ini sejalan dengan peningkatan yang sangat pesat dalam transaksi e-commerce, transaksi pembayaran digital juga meningkat pesat yang tercermin dari peningkatan jumlah penggunaan uang elektronik (UE) dalam transaksi $e$ commerce. Peningkatan jumlah uang elektronik ini menyebabkan pasar harus menggunakan uang elektronik dalam setiap transaksi e-commerce yang dilakukan. Sejak triwulan pertama tahun 2019 hingga triwulan ke-3 tahun 2020 penggunaan uang elektronik (transaksi $e$ commerce) semakin meningkat. Data penggunaan uang elektronik pada triwulan ke-4 tahun 2020 mencapai $41,71 \%$, jauh melebihi pasar yang menggunakan metode transfer bank yang hanya mencapai sekitar 20,23\% dan setoran tunai yang hanya mencapai sekitar 19,01\%. Dengan meningkatnya kebutuhan jumlah e-commerce di Indonesia, tentu peran digital signature sangat diperlukan untuk mempercepat proses transaksi digital.

Digital signature memiliki beberapa fungsi, diantaranya adalah memastikan integritas dan keamanan dokumen, konfirmasi kepemilikan dokumen yang akurat, serta sebagai bukti yang valid dan legal dalam melakukan setiap transaksi [9]. Proses penandatanganan dokumen secara konvensional memiliki berbagai macam kendala terutama pada situasi pandemi COVID19 saat ini, dimana penandatangan harus dilakukan di lokasi yang sama dengan dokumen yang bersangkutan, serta meningkatkan pemalsuan dokumen dengan menyalin tanda tangan dan identitas pribadi. Solusi untuk semua masalah keamanan pada tanda tangan konvensional adalah beralih menggunakan sistem tanda tangan digital. Tanda tangan digital merupakan algoritma matematika untuk menghasilkan tanda tangan guna memastikan privasi percakapan, integritas data, keaslian pesan digital dan keaslian pengirim dokumen. Tanda tangan digital ini merupakan salah satu transaksi elektronik yang memerlukan kerahasiaan informasi dan legalitas dokumen sehingga Pemerintah Republik Indonesia mengeluarkan Undang-Undang Nomor 11 Tahun 2008 tentang Sistem Informasi Elektronik dan Penyelenggaraan Transaksi untuk melegalkan transaksi elektronik dalam penyelenggaraan tanda tangan digital [10]. Berkaitan dengan keamanan transaksi elektronik dilindungi dalam PP 82/2012 bahwa dokumen elektronik dan informasi elektronik wajib menjaga kerahasiaan, keaslian, aksesibilitas, dan ketersediaannya oleh penyelenggara sistem elektronik sesuai dengan ketentuan peraturan tersebut (Pasal 22 (1) PP 82/2012). Penerapan kombinasi keaslian pada tanda tangan elektronik untuk verifikasi identitas penandatangan diwajibkan oleh penyelenggara sistem elektronik (Pasal 58 (2) PP 82/2012).

Menurut penelitian yang dilakukan oleh Yusup et al. [11] yang membahas mengenai dampak sosio-ekonomi dalam pengadopsian tanda tangan digital menggunakan aplikasi blockchain. Hasil dari penelitian ini menjelaskan bahwa implementasi blockchain sosioekonomi terhadap penggunaan sistem tanda tangan digital sangat berpengaruh dalam sistem penerbitan sertifikat. Dalam hal ini faktor keamanan data (security), sentralisasi data (autonomy), dan data yang terintegrasi (data integrity) merupakan faktor-faktor yang sangat menonjol pada pengadopsian blockchain terhadap implementasi sistem teknologi e-certificate untuk aktivitas penerbitan sertifikat. Pada penelitian lainnya yang dilakukan oleh Dermawan [12] yang membahas mengenai pemanfaatan tanda tangan digital tersertifikasi di era pandemi yang menjelaskan bahwa jaminan privasi dan perlindungan dalam hal data pribadi pengguna sistem tanda tangan digital menjadi hal utama yang harus diperhatikan, hal tersebut dikarenakan masyarakat khawatir terhadap pencurian data pribadi mereka yang dapat disalahgunakan oleh pihak yang tidak bertanggung jawab. Kekhawatiran masyarakat ini didasari oleh kejahatan dunia maya (cyber crime) semakin meningkat setiap tahunnya. Kemudian, menurut penelitian yang dilakukan oleh Chong et al. [13] yang membahas mengenai faktor yang mempengaruhi minat pelanggan untuk mengadopsi layanan tanda tangan digital yang menggunakan cloudtechnology. Penelitian ini menggabungkan dua teori menjadi kesatuan framework yaitu 
technology acceptance model (TAM) dan technology organization environment (TOE), dimana penelitian ini menghasilkan faktor dominan yang mempengaruhi konsumen untuk mengadopsi sistem tanda tangan digital, dimana faktor karakteristik ekonomi menjadi faktor yang paling dominan dalam penelitian ini, kemudian diikuti oleh faktor lingkungan, organisasi, dan teknis.

Berdasarkan penelitian terdahulu yang telah dijelaskan, maka peneliti tertarik untuk melakukan penelitian yang berkaitan dengan dimensi ekonomi, lingkungan, dan sosial terhadap pemilihan platform tanda tangan digital, dimana ketiga dimensi tersebut merupakan landasan utama dalam konsep keberlanjutan (sustainability). Kemudian untuk metode yang digunakan adalah metode Analytical Hierarchy Process (AHP), dimana framework dari metode AHP yang dibangun dalam penelitian ini belum ada peneliti sebelumnya yang mengimplementasikan metode AHP di dalam topik ini. Analytical Hierarchy Process (AHP) merupakan suatu metode analisis yang dikembangkan oleh Dr. Thomas L. Saaty pada tahun 1980. Prinsip utama metode AHP adalah proses pengolahan data yang digunakan untuk pengambilan keputusan dalam memilih alternatif dengan cepat secara konsisten [14]. AHP merupakan suatu fasilitas pengambilan keputusan tidak hanya untuk menyederhanakan permasalahan yang sedang diteliti, tetapi juga dapat mempresentasikannya dalam bentuk struktur hierarki. AHP mudah digunakan dan memungkinkan para pengambil keputusan untuk mengukur tingkat konsistensi dalam mengevaluasi masalah keputusan. Metode AHP memiliki kelebihan dibandingkan dengan metode lainnya, yaitu struktur analisis dalam AHP ditampilkan dalam bentuk grafis sehingga seluruh pihak yang terlibat dalam pengambilan keputusan dapat dengan mudah memahami tujuan penelitian yang ingin dicapai [15]. Kelebihan lainnya dari metode AHP adalah mampu menyelesaikan persoalan dalam suatu kerangka berpikir yang terorganisir sehingga dapat mengambil keputusan secara efektif terhadap suatu permasalahan. Selain itu, metode AHP dapat melakukan pengecekan terhadap hasil evaluasi perbandingan antara kriteria sehingga proses analisis dilakukan secara subjektif dan mampu menghasilkan bobot kriteria serta evaluasi bobot alternatif keputusan yang lebih akurat [16]. Di sisi lain, metode AHP juga memiliki kelemahan yaitu data input utama menjadi hal yang sangat perlu dipertimbangkan sehingga menimbulkan ketergantungan terhadap data input utamanya [17]. Ada beberapa tahapan dalam menyelesaikan permasalahan menggunakan metode AHP, yaitu mendefinisikan permasalahan dan menentukan solusi yang diharapkan, membangun struktur hierarki terhadap tujuan penelitian, membuat matriks perbandingan berpasangan, menentukan prioritas elemen, menghitung sistesis terhadap perbandingan berpasangan, serta mengurutkan kriteria atau sub-kriteria berdasarkan nilai prioritas [18].

Penelitian ini bertujuan untuk mendapatkan sub-kriteria yang berpengaruh terhadap tujuan penelitian yang telah ditentukan dan menjadi fokus dalam pengambilan keputusan, setelah mendapatkan hasil dari sub-kriteria yang menjadi prioritas dan menemukan platform tanda tangan digital yang menjadi favorit bagi para ahli, terutama pada saat pandemi COVID-19 saat ini karena kebutuhan penggunaan tanda tangan digital yang semakin meningkat dengan adanya pemberlakuan pembatasan kegiatan masyarakat (PPKM) di Indonesia. Oleh karena itu, berdasarkan tujuan penelitian, maka peneliti melakukan analisis faktor sustainability yang menjadi prioritas dalam menggunakan sistem tanda tangan digital menggunakan metode AHP yang memberikan pengetahuan bagi masyarakat umum dan khususnya bagi para pihak penyelenggara sistem tanda tangan digital.

\section{Metode Penelitian}

\subsection{Langkah Penelitian}

Adapun teknik analisis AHP terbagi menjadi beberapa langkah pengerjaan adalah sebagai berikut:

a. Mendefinisikan tujuan penelitian

Tujuan dari penelitian ini adalah untuk mengetahui faktor yang menjadi prioritas dari sub-kriteria dalam dimensi sustainability yang dapat memudahkan pihak penyelenggara sistem tanda tangaan digital untuk mengambil keputusan dan berinovasi dalam memperbaharui sistem tanda tangan digital yang dibangun agar pihak penyelenggara teknologi dapat mencapai 
sustainability dalam bisnis pengembangan teknologi yang dijalankan. Selanjutnya, mencari platform yang menjadi favorit bagi para ahli sebagai dasar dalam pemilihan sistem tanda tangan digital. Berdasarkan definisi tujuan penelitian tersebut, maka dipilih kriteria dan sub-kriteria untuk membantu dalam membangun struktur hierarki berdasarkan dimensi sustainability.

b. Pengumpulan data

Pengumpulan data dilakukan di Batam dengan melibatkan beberapa ahli dari latar belakang yang berbeda menggunakan formulir data berupa kuesioner penilaian berdasarkan tabel atau matriks. Para ahli yang terlibat merupakan pengguna sistem tanda tangan digital secara rutin sebagai sarana teknologi alternatif dalam melakukan verifikasi dan otentifikasi dokumen yang diterima dan dokumen yang akan dikirimkan kepada pihak yang bersangkutan. Berdasarkan hasil kuesioner tersebut, rating atau penilaian berpasangan diantara faktor-faktor tersebut diperoleh dengan menggunakan sembilan poin skala Saaty yang dapat dilihat pada Tabel 1 berikut ini:

Tabel 1. Skala Penilaian Kriteria dalam AHP

\begin{tabular}{cc}
\hline Skor & Keterangan \\
\hline $\mathbf{1}$ & Kedua faktor sama pentingnya \\
\hline $\mathbf{3}$ & Satu faktor yang cukup penting dibanding faktor lainnya \\
\hline $\mathbf{5}$ & Satu faktor yang penting dibanding faktor lainnya \\
\hline $\mathbf{7}$ & Satu faktor yang sangat penting dibanding faktor lainnya \\
\hline $\mathbf{9}$ & Satu faktor yang paling penting dibanding faktor lainnya \\
\hline $\mathbf{2 , 4 , 6 , 8}$ & Nilai tengah antara dua nilai yang berdekatan \\
\hline
\end{tabular}

Kerangka matriks penilaian berpasangan ditentukan untuk mengetahui bobot kepentingan dari faktor-faktor tersebut. Berdasarkan bobot kepentingan yang dicapai, maka diperoleh prioritas untuk masing-masing faktor berdasarkan formula yang dikembangkan oleh Saaty pada tahun 1980. Sembilan poin yang digunakan membantu dalam mengukur nilai $\alpha i j$ (elemen pada matriks penilaian berpasangan) diubah dari penilaian verbal. Nilai aij ditunjukkan pada persamaan dibawah ini:

$\alpha i j>0 ; \quad \alpha j i=1 / \alpha i j ; \quad \alpha i i=1$ untuk semua nilai ' $\mathrm{i}$ '

c. Menganalisis data

Analisis data dilakukan dengan mengumpulkan hasil formulir kuesioner yang telah diisi oleh para ahli untuk kemudian dianalisis dan dilakukan perhitungan menggunakan metode AHP. Pada tahap analisis ini peneliti menggunakan tabel skala penilaian kriteria, tabel Random Index Consistency (RI), normalisasi, serta perangkingan prioritas berdasarkan persentase sub-kriteria. Untuk memperoleh nilai konsistensi hierarki maka harus mendapatkan keputusan dengan nilai konsistensi yang rendah. Berikut ini adalah rumus perhitungan Consistency Index (CI):

$\mathrm{CI}=[(\lambda$ maks $-\mathrm{n}) /(\mathrm{n}-1)]$

Dimana, $\mathrm{n}=$ Total elemen,

$\lambda$ maks $=$ Nilai rata-rata maksimum dari matriks perbandingan yang berpasangan.

Cara perhitungan Consistency Ratio (CR) adalah sebagai berikut:

$\mathrm{CR}=\mathrm{CI} / \mathrm{RI}$

Dimana, $\mathrm{CR}=$ Consistency Ratio,

$\mathrm{CI}=$ Consistency Index,

$\mathrm{RI}=$ Random Index Consistency.

Nilai Random Index Consistency (RI) dapat dipilih dari Tabel 2 dibawah ini, dimana nilai RI tergantung pada nilai ' $n$ '. Jika nilai CR lebih dari $10 \%(\mathrm{CR}>0,1)$ maka penilaian data harus diperbaiki, namun jika nilai $\mathrm{CR}$ kurang atau sama dengan $10 \%(\mathrm{CR} \leq 0,1)$, maka hasil perhitungan dinyatakan konsisten [19]. 
Tabel 2. Daftar Random Index Consistency (RI)

\begin{tabular}{ccccccccccccc}
\hline $\mathbf{n}$ & $\mathbf{1}$ & $\mathbf{2}$ & $\mathbf{3}$ & $\mathbf{4}$ & $\mathbf{5}$ & $\mathbf{6}$ & $\mathbf{7}$ & $\mathbf{8}$ & $\mathbf{9}$ & $\mathbf{1 0}$ & $\mathbf{1 1}$ & $\mathbf{1 2}$ \\
\hline $\mathbf{R I}$ & 0,00 & 0,00 & 0,58 & 0,90 & 1,12 & 1,24 & 1,32 & 1,41 & 1,45 & 1,49 & 1,51 & 1,48 \\
\hline
\end{tabular}

\section{Hasil dan Pembahasan}

Analisis AHP dilakukan dengan tujuan adalah menentukan kepentingan relatif dari setiap faktor-faktor dalam implementasi sustainability untuk mengembangkan sistem tanda tangan digital. Berdasarkan hasil observasi dan wawancara yang dilakukan dengan beberapa orang ahli, maka dibentuk struktur keputusan hierarki seperti yang ditunjukkan pada Gambar 1. Pada dasarnya struktur keputusan hierarki terdiri dari empat tingkatan, yaitu tujuan penelitian (mengukur intervensi antar setiap faktor) yang ditunjukkan pada Tingkat 1 , selanjutnya adalah kriteria (faktor utama) yang ditunjukkan pada Tingkat 2, sub-kriteria (sub-faktor) yang ditunjukkan pada Tingkat 3, dan alternatif platform tanda tangan digital pada Tingkat 4. Struktur hierarki AHP berdasarkan sub-kriteria dari dimensi sustainability yang mempengaruhi keberlanjutan sistem tanda tangan digital dapat dilihat pada Gambar 1 dibawah ini:

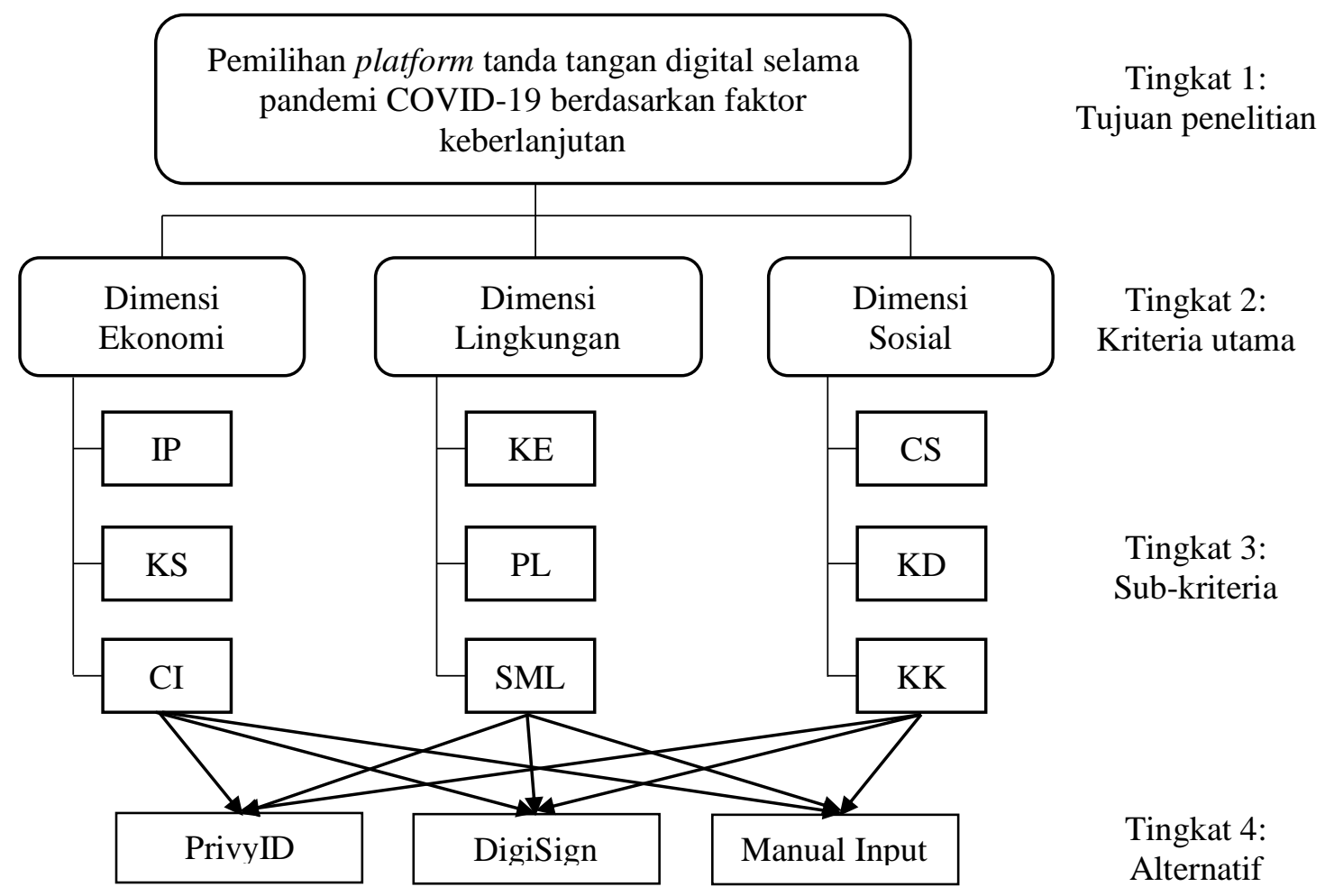

Gambar 1. Struktur Hierarki Kriteria Prioritas Berdasarkan Dimensi Sustainability

Untuk merumuskan hierarki model AHP yang sesuai yang terdiri dari tujuan, kriteria, dan sub-kriteria serta alternatifnya. Tujuan penelitian ini adalah untuk memudahkan pihak penyelenggara untuk mengambil keputusan dan berinovasi dalam memperbaharui sistem tanda tangan digital yang dibangun agar dapat mencapai sustainability dalam bisnis tanda tangan digital yang dikembangkan berdasarkan dimensi ekonomi, lingkungan, dan sosial. Tujuan ini ditempatkan pada tingkat pertama dari hierarki seperti yang ditunjukkan pada Gambar 1. Tiga kriteria utama, yaitu dimensi ekonomi, lingkungan, dan sosial diidentifikasi untuk mencapai tujuan ini, yang membentuk hierarki tingkat kedua. Faktor ekonomi menjadi penting karena semakin rendah biaya suatu jasa atau produk maka semakin tinggi produktivitas dan efisiensinya, sehingga mendatangkan keuntungan yang lebih besar bagi perusahaan. Pada tingkat ketiga terdiri dari sub-kriteria faktor ekonomi ini terdiri dari sub-kriteria inovasi produk (IP), kualitas sistem (KS), dan continuous improvement (CI). Sedangkan untuk sub-kriteria dari 
faktor lingkungan juga penting karena lebih berfokus pada dampak penggunaan sistem tanda tangan digital terhadap lingkungan. Faktor lingkungan ini terdiri dari sub-kriteria konsumsi energi (KE), pengurangan limbah (PL), dan sistem manajemen lingkungan (SML). Selain itu, sub-kriteria pada faktor sosial juga termasuk aspek penting yang harus diperhatikan dalam melaksanakan proses pengembangan sistem agar proses pengembangan sistem dapat berjalan dengan lancar dan aman. Faktor sosial ini terdiri dari sub-kriteria customer service (CS), keamanan data pengguna (KD), dan kemudahan komunikasi antar pengguna (KK). Pada tingkat keempat terdiri dari tiga alternatif platform tanda tangan digital yang telah ditentukan, yaitu platform PrivyID, DigiSign, dan Manual input.

Pemilihan platform PrivyID didasari oleh suatu layanan publik berupa platform tanda tangan elektronik yang memiliki kekuatan hukum yang sah sesuai dengan persyaratan UU ITE dan telah tersertifikasi oleh KOMINFO sebagai salah satu penyelenggara sertifikat elektronik (PSrE) resmi di Indonesia [20]. Di sisi lain, pemilihan platform DigiSign didasari oleh suatu layanan publik yang berfungsi untuk tanda tangan elektronik dan stempel waktu yang dilekatkan pada setiap dokumen atau transaksi elektronik yang didukung oleh enkripsi berstandar Internasional dan keotentikan data entitas pelanggan, serta telah tersertifikasi oleh KOMINFO sebagai salah satu penyelenggara sertifikat elektronik (PSrE) resmi di Indonesia [20]. Sedangkan pemilihan Manual input didasari oleh penggunaan tanda tangan elektronik secara gratis untuk menandatangani dokumen tanpa perlu menggunakan platform penyedia tanda tangan digital. Cara yang paling sering digunakan untuk tanda tangan elektronik ini adalah memasukkan tanda tangan secara manual ke dalam Microsoft word atau Portable Document Format (PDF) melalui aplikasi Adobe Acrobat DC [21].

Tabel 3. Sub-kriteria dalam Dimensi Sustainability

\begin{tabular}{|c|c|c|c|}
\hline Dimensi & Kode & Sub-kriteria & Keterangan \\
\hline \multirow{3}{*}{$\begin{array}{l}\text { Dimensi } \\
\text { Ekonomi } \\
\text { (DE) }\end{array}$} & IP & Inovasi Produk & Produk baru untuk membidik pelanggan baru \\
\hline & $\mathrm{KS}$ & Kualitas Sistem & $\begin{array}{c}\text { Periode purna jual sistem tanda tangan digital } \\
\text { yang dapat dipertahankan }\end{array}$ \\
\hline & $\mathrm{CI}$ & $\begin{array}{l}\text { Continuous } \\
\text { Improvement }\end{array}$ & $\begin{array}{l}\text { Perbaikan sistem terus-menerus secara } \\
\text { bertahap dalam kualitas sistem, biaya } \\
\text { berlangganan, dan daya tanggap sistem }\end{array}$ \\
\hline \multirow{3}{*}{$\begin{array}{l}\text { Dimensi } \\
\text { Lingkungan } \\
\text { (DL) }\end{array}$} & $\mathrm{KE}$ & Konsumsi Energi & $\begin{array}{l}\text { Energi yang diperlukan untuk menggunakan } \\
\text { sistem tanda tangan digital }\end{array}$ \\
\hline & PL & $\begin{array}{l}\text { Pengurangan } \\
\text { Limbah }\end{array}$ & $\begin{array}{l}\text { Dampak terhadap limbah yang berkurang } \\
\text { ketika menggunakan tanda tangan digital }\end{array}$ \\
\hline & SML & $\begin{array}{l}\text { Sistem Manajemen } \\
\text { Lingkungan }\end{array}$ & $\begin{array}{c}\text { Kebijakan dalam standar manajemen } \\
\text { lingkungan, Pengembangan sistem dengan } \\
\text { dampak lingkungan yang kecil }\end{array}$ \\
\hline \multirow{3}{*}{$\begin{array}{l}\text { Dimensi } \\
\text { Sosial } \\
\text { (DS) }\end{array}$} & $\mathrm{CS}$ & Customer Service & $\begin{array}{l}\text { Upaya menjalin komunikasi dengan baik } \\
\text { dengan para pengguna tanda tangan digital }\end{array}$ \\
\hline & $\mathrm{KD}$ & $\begin{array}{l}\text { Keamanan Data } \\
\text { Pengguna }\end{array}$ & $\begin{array}{l}\text { Data pengguna terlindungi dari cybercrime dan } \\
\text { aman dari pihak yang tidak bertanggung jawab }\end{array}$ \\
\hline & KK & $\begin{array}{l}\text { Kemudahan } \\
\text { Komunikasi antar } \\
\text { Pengguna }\end{array}$ & $\begin{array}{l}\text { Kondisi sistem tanda tangan digital yang } \\
\text { efektif dan kelengkapan fasilitas/fitur sehingga } \\
\text { memudahkan para pengguna untuk saling } \\
\text { berkomunikasi }\end{array}$ \\
\hline
\end{tabular}

Untuk menganalisis tingkat prioritas pada kriteria utama dilakukan dengan cara membuat matriks perbandingan kriteria, dalam matriks perbandingan kriteria tersebut diisi dengan nilai yang menunjukkan perbandingan antara kriteria satu dengan kriteria lainnya yang 
saling berhubungan (lihat Tabel 4). Pengisian nilai perbandingan kriteria menggunakan skala penilaian hierarki AHP yang terdapat pada Tabel 1. Dimana nilai bulat pada kolom yang terdapat didalam tabel matriks perbandingan kriteria menyatakan bahwa kriteria tersebut memiliki nilai lebih unggul dibandingkan dengan kriteria lainnya. Sedangkan nilai kriteria yang berlawanan diisi dengan kebalikan dari nilai bulat tersebut.

Pada Tabel 4 dibawah ini merupakan penilaian yang diperoleh dari hasil kuesioner yang diisi oleh beberapa orang ahli mengenai faktor sustainability yang dapat menunjang penggunaan sistem tanda tangan digital.

Tabel 4. Matriks Perbandingan Kriteria

\begin{tabular}{cccc}
\hline Kriteria Utama & $\begin{array}{c}\text { Dimensi } \\
\text { Ekonomi (DE) }\end{array}$ & $\begin{array}{c}\text { Dimensi } \\
\text { Lingkungan (DL) }\end{array}$ & $\begin{array}{c}\text { Dimensi Sosial } \\
\text { (DS) }\end{array}$ \\
\hline Dimensi Ekonomi (DE) & 1 & 0,333 & 0,200 \\
Dimensi Lingkungan (DL) & 3 & 1 & 0,333 \\
Dimensi Sosial (DS) & 5 & 3 & 1 \\
\hline Jumlah Nilai Sintesis & 9 & 4,333 & 1,533 \\
\hline
\end{tabular}

Hasil nilai matriks perbandingan kriteria diatas diperoleh dari perhitungan dibawah ini sebagai dasar dalam menentukan skala prioritas:

- Pada baris 1 kolom 1, DE-DE $=1$

- Pada baris 1 kolom 2, DE-DL $=1 / 3=0,333$

- Pada baris 1 kolom 3, DE-DS $=1 / 5=0,200$

- Pada baris 2 kolom 1, DL-DE $=3$

- Pada baris 2 kolom 2, DL-DL $=1$

- Pada baris 2 kolom 3, DL-DS $=1 / 3=0,333$

- Pada baris 3 kolom 1, DS-DE $=5$

- Pada baris 3 kolom 2, DS-DL $=3$

- Pada baris 3 kolom 3, DS-DS = 1

\subsection{Matriks Perbandingan Sub-kriteria}

Perhitungan nilai perbandingan untuk setiap sub-kriteria didalam kriteria dimensi sustainability berdasarkan urutan dalam struktur dasar hierarki AHP adalah sebagai berikut:

Tabel 5. Sintesis Matriks Perbandingan Sub-kriteria

\begin{tabular}{cccccccccc}
\hline $\begin{array}{c}\text { Sub- } \\
\text { Kriteria }\end{array}$ & $\mathbf{I P}$ & $\mathbf{K S}$ & $\mathbf{C I}$ & $\mathbf{K E}$ & $\mathbf{P L}$ & $\mathbf{S M L}$ & $\mathbf{C S}$ & KD & KK \\
\hline $\mathbf{I P}$ & 1 & 0,333 & 0,333 & 0,5 & 3 & 2 & 0,333 & 0,333 & 5 \\
$\mathbf{K S}$ & 3 & 1 & 0,333 & 3 & 3 & 4 & 2 & 2 & 4 \\
$\mathbf{C I}$ & 3 & 3 & 1 & 2 & 4 & 3 & 3 & 4 & 5 \\
KE & 2 & 0,333 & 0,5 & 1 & 2 & 3 & 2 & 0,5 & 3 \\
$\mathbf{P L}$ & 0,333 & 0,333 & 0,25 & 0,5 & 1 & 2 & 0,5 & 0,333 & 4 \\
SML & 0,5 & 0,25 & 0,333 & 0,333 & 0,5 & 1 & 0,333 & 0,2 & 0,5 \\
CS & 3 & 0,5 & 0,333 & 0,5 & 2 & 3 & 1 & 0,333 & 4 \\
KD & 3 & 0,5 & 0,25 & 2 & 3 & 5 & 3 & 1 & 3 \\
KK & 0,2 & 0,25 & 0,2 & 0,333 & 0,25 & 2 & 0,25 & 0,333 & 1 \\
\hline Jumlah & 16,033 & 6,499 & 3,532 & 10,166 & 18,75 & 25 & 12,416 & 9,032 & 29,5 \\
\hline
\end{tabular}

Pengisian nilai pada baris dan kolom dari masing-masing sub-kriteria diatas yaitu dengan cara perhitungan kebalikan dari nilai bulat yang diperoleh dari data survei sebelumnya. Setelah menghitung sintesis matriks perbandingan dari setiap sub-kriteria dalam dimensi sustainability, kemudian menghitung nilai normalisasi untuk setiap sub-kriteria pada dimensi sustainability.

Tabel 6. Normalisasi 


\begin{tabular}{ccccccccccc}
\hline $\begin{array}{c}\text { Sub- } \\
\text { Kriteria }\end{array}$ & IP & KS & CI & KE & PL & SML & CS & KD & KK & Jumlah \\
\hline IP & 0,062 & 0,051 & 0,094 & 0,049 & 0,160 & 0,080 & 0,027 & 0,037 & 0,169 & 0,730 \\
KS & 0,187 & 0,154 & 0,094 & 0,295 & 0,160 & 0,160 & 0,161 & 0,221 & 0,136 & 1,568 \\
CI & 0,187 & 0,462 & 0,283 & 0,197 & 0,213 & 0,120 & 0,242 & 0,443 & 0,169 & 2,316 \\
KE & 0,125 & 0,051 & 0,142 & 0,098 & 0,107 & 0,120 & 0,161 & 0,055 & 0,102 & 0,961 \\
PL & 0,021 & 0,051 & 0,071 & 0,049 & 0,053 & 0,080 & 0,040 & 0,037 & 0,136 & 0,538 \\
SML & 0,031 & 0,038 & 0,094 & 0,033 & 0,027 & 0,040 & 0,027 & 0,022 & 0,017 & 0,329 \\
CS & 0,187 & 0,077 & 0,094 & 0,049 & 0,107 & 0,120 & 0,081 & 0,037 & 0,136 & 0,887 \\
KD & 0,187 & 0,077 & 0,071 & 0,197 & 0,160 & 0,200 & 0,242 & 0,111 & 0,102 & 1,346 \\
KK & 0,012 & 0,038 & 0,057 & 0,033 & 0,013 & 0,080 & 0,020 & 0,037 & 0,034 & 0,325 \\
\hline Jumlah & 1 & 1 & 1 & 1 & 1 & 1 & 1 & 1 & 1 & 9 \\
\hline
\end{tabular}

Hasil yang ditunjukkan pada tabel normalisasi sub-kriteria didalam dimensi ekonomi terdiri dari 3 (tiga) sub-kriteria, lingkungan terdiri dari 3 (tiga) sub-kriteria, dan sosial terdiri dari 3 (tiga) sub-kriteria. Setelah terbentuknya tabel sintesis matriks perbandingan pada setiap dimensi sustainability, kemudian menghitung nilai rata-rata dari setiap sub-kriteria berdasarkan jumlah nilai pada setiap baris sub-kriteria dan dibagi dengan jumlah sub-kriteria dari masingmasing dimensi sustainability. Setelah mendapatkan nilai rata-rata dari setiap sub-kriteria, maka nilai rata-rata tersebut dapat digunakan untuk mengurutkan rangking prioritas sub-kriteria.

Tabel 7. Perangkingan Prioritas Sub-Kriteria

\begin{tabular}{cccc}
\hline Sub-Kriteria & Prioritas & Persentase Prioritas $(\%)$ & Rangking Prioritas \\
\hline CI & 0,257 & 25,7 & 1 \\
KS & 0,174 & 17,4 & 2 \\
KD & 0,150 & 15 & 3 \\
KE & 0,107 & 10,7 & 4 \\
CS & 0,099 & 9,9 & 5 \\
IP & 0,081 & 8,1 & 6 \\
PL & 0,060 & 6 & 7 \\
SML & 0,037 & 3,7 & 8 \\
KK & 0,036 & 3,6 & 9 \\
\hline Jumlah & 1 & 100 & \\
\hline
\end{tabular}

Pengisian rangking prioritas sub-kriteria pada Tabel 7 diatas menggunakan jumlah nilai dari masing-masing data normalisasi sub-kriteria yang terdapat pada Tabel 6. Berikut ini adalah nilai rata-rata prioritas dari setiap sub-kriteria pada dimensi sustainability:
- IP $=0,730 / 9=0,081$
- $\mathrm{KS}=1,568 / 9=0,174$
- $\mathrm{CI} \quad=2,316 / 9=0,257$
- $\mathrm{KE}=0,961 / 9=0,107$
- PL $=0,538 / 9=0,060$
- $\mathrm{SML}=0,329 / 9=0,037$
- $\mathrm{CS}=0,887 / 9=0,099$
- $\mathrm{KD}=1,346 / 9=0,150$
- $\mathrm{KK}=0,325 / 9=0,036$

\subsection{Perhitungan Konsistensi Hierarki}

Dalam analisis AHP ini diperlukan pengujian Consistency Ratio (CR) untuk mengukur seluruh konsistensi penilaian, dimana nilai konsistensi hierarki suatu matriks perbandingan 
dinilai konsisten jika nilai CR tidak lebih dari $10 \%$ atau $\mathrm{CR} \leq 0,1$. Untuk dapat menghitung $\mathrm{CR}$ maka harus mendapatkan nilai CI terlebih dahulu dengan perhitungan sebagai berikut:

Consistency index $(\mathrm{CI})=[(\lambda$ maks $-\mathrm{n}) /(\mathrm{n}-1)]$

$$
\begin{aligned}
\lambda \text { maks }= & ((16,033 * 0,081)+(6,499 * 0,174)+(3,532 * 0,257)+(10,166 * 0,107)+ \\
& (18,750 * 0,060)+(25 * 0,037)+(12,416 * 0,099)+(9,032 * 0,150)+ \\
& (29,5 * 0,036)) \\
= & 10,101 \\
\operatorname{dex}(\mathrm{CI})= & {[(10,101-9) /(9-1)] } \\
= & 0,138
\end{aligned}
$$

Consistency index $(\mathrm{CI})=[(10,101-9) /(9-1)]$

Hasil nilai CI yang diperoleh adalah 0,138 , maka tahap berikutnya adalah menentukan nilai Consistency Ratio (CR), dimana untuk menghitung nilai CR harus menentukan nilai RI terlebih dahulu sesuai dengan jumlah sub-kriteria (n) yang telah ditentukan. Jumlah sub-kriteria tersebut adalah 9 sehingga nilai jumlah kriteria didapat $\mathrm{n}=9$ dengan nilai $\mathrm{RI}=1,45$ sesuai dengan tabel Random Index Consistency (RI). Maka nilai CR adalah sebagai berikut:

$\mathrm{CR}=\mathrm{CI} / \mathrm{RI}=0,138 / 1,45=0,0952$.

Berdasarkan hasil perhitungan nilai CR diatas diperoleh nilai 0,0952 yang berarti bahwa nilai tersebut memenuhi syarat karena nilai $C R \leq 0,1$. Sehingga diketahui bahwa proses penentuan prioritas sub-kriteria terhadap penggunaan sistem tanda tangan digital dinyatakan konsisten.

\subsection{Perhitungan Bobot Alternatif}

Dalam menentukan alternatif sistem tanda tangan digital yang lebih unggul antara alternatif yang satu dengan lainnya, diperlukan perhitungan nilai eigen dari masing-masing subkriteria terhadap tiga alternatif yang telah ditentukan, yaitu PrivyID, DigiSign, dan Manual Input. Berikut ini adalah hasil kuesioner berdasarkan masing-masing sub-kriteria sustainability:

1. Matriks perbandingan alternatif sub-kriteria IP

Berikut ini adalah nilai perbandingan alternatif platform tanda tangan digital berdasarkan sub-kriteria inovasi produk, dapat dilihat pada tabel dibawah ini:

Tabel 8. Matriks Perbandingan Alternatif Berdasarkan Sub-kriteria IP

\begin{tabular}{cccc}
\hline Alternatif & PrivyID & DigiSign & Manual Input \\
\hline PrivyID & 1 & 0,333 & 5 \\
DigiSign & 3 & 1 & 5 \\
Manual Input & 0,2 & 0,2 & 1 \\
\hline Jumlah & 4,200 & 1,533 & 11 \\
\hline
\end{tabular}

Tabel 9. Normalisasi Sub-kriteria IP terhadap Alternatif

\begin{tabular}{ccccc}
\hline Alternatif & PrivyID & DigiSign & Manual Input & Rata-rata \\
\hline PrivyID & 0,238 & 0,217 & 0,455 & 0,303 \\
DigiSign & 0,714 & 0,652 & 0,455 & 0,607 \\
Manual Input & 0,048 & 0,131 & 0,090 & 0,090 \\
\hline Jumlah & 1 & 1 & 1 & 1 \\
\hline
\end{tabular}

2. Matriks perbandingan alternatif sub-kriteria KS

Nilai perbandingan alternatif platform tanda tangan digital berikutnya adalah berdasarkan sub-kriteria kualitas sistem, dapat dilihat pada tabel dibawah ini:

Tabel 10. Matriks Perbandingan Alternatif Berdasarkan Sub-kriteria KS

\begin{tabular}{cccc}
\hline Alternatif & PrivyID & DigiSign & Manual Input \\
\hline PrivyID & 1 & 3 & 5 \\
DigiSign & 0,333 & 1 & 5 \\
Manual Input & 0,2 & 0,2 & 1 \\
\hline Jumlah & 1,533 & 4,200 & 11 \\
\hline
\end{tabular}


Tabel 11. Normalisasi Sub-kriteria KS terhadap Alternatif

\begin{tabular}{ccccc}
\hline Alternatif & PrivyID & DigiSign & Manual Input & Rata-rata \\
\hline PrivyID & 0,652 & 0,714 & 0,455 & 0,607 \\
DigiSign & 0,217 & 0,238 & 0,455 & 0,303 \\
Manual Input & 0,131 & 0,048 & 0,090 & 0,090 \\
\hline Jumlah & 1 & 1 & 1 & 1 \\
\hline
\end{tabular}

3. Matriks perbandingan alternatif sub-kriteria CI

Nilai perbandingan alternatif platform tanda tangan digital berikutnya adalah berdasarkan sub-kriteria continuous improvement, dapat dilihat pada tabel dibawah ini:

Tabel 12. Matriks Perbandingan Alternatif Berdasarkan Sub-kriteria CI

\begin{tabular}{cccc}
\hline Alternatif & PrivyID & DigiSign & Manual Input \\
\hline PrivyID & 1 & 0,25 & 3 \\
DigiSign & 4 & 1 & 3 \\
Manual Input & 0,333 & 0,333 & 1 \\
\hline Jumlah & 5,333 & 1,583 & 7 \\
\hline
\end{tabular}

Tabel 13. Normalisasi Sub-kriteria CI terhadap Alternatif

\begin{tabular}{ccccc}
\hline Alternatif & PrivyID & DigiSign & Manual Input & Rata-rata \\
\hline PrivyID & 0,188 & 0,158 & 0,429 & 0,258 \\
DigiSign & 0,750 & 0,632 & 0,429 & 0,603 \\
Manual Input & 0,062 & 0,210 & 0,142 & 0,139 \\
\hline Jumlah & 1 & 1 & 1 & 1 \\
\hline
\end{tabular}

4. Matriks perbandingan alternatif sub-kriteria KE

Nilai perbandingan alternatif platform tanda tangan digital berikutnya adalah berdasarkan sub-kriteria konsumsi energi, dapat dilihat pada tabel dibawah ini:

Tabel 14. Matriks Perbandingan Alternatif Berdasarkan Sub-kriteria KE

\begin{tabular}{cccc}
\hline Alternatif & PrivyID & DigiSign & Manual Input \\
\hline PrivyID & 1 & 3 & 0,333 \\
DigiSign & 0,333 & 1 & 0,333 \\
Manual Input & 3 & 3 & 1 \\
\hline Jumlah & 4,333 & 7 & 1,666 \\
\hline
\end{tabular}

Tabel 15. Normalisasi Sub-kriteria KE terhadap Alternatif

\begin{tabular}{ccccc}
\hline Alternatif & PrivyID & DigiSign & Manual Input & Rata-rata \\
\hline PrivyID & 0,231 & 0,429 & 0,200 & 0,286 \\
DigiSign & 0,077 & 0,142 & 0,200 & 0,140 \\
Manual Input & 0,692 & 0,429 & 0,600 & 0,574 \\
\hline Jumlah & 1 & 1 & 1 & 1 \\
\hline
\end{tabular}

5. Matriks perbandingan alternatif sub-kriteria PL

Nilai perbandingan alternatif platform tanda tangan digital berdasarkan sub-kriteria pengurangan limbah, dapat dilihat pada tabel dibawah ini:

Tabel 16. Matriks Perbandingan Alternatif Berdasarkan Sub-kriteria PL

\begin{tabular}{cccc}
\hline Alternatif & PrivyID & DigiSign & Manual Input \\
\hline PrivyID & 1 & 0,2 & 3 \\
DigiSign & 5 & 1 & 4 \\
Manual Input & 0,333 & 0,25 & 1 \\
\hline
\end{tabular}




\begin{tabular}{llll}
\hline Jumlah & 6,333 & 1,450 & 8 \\
\hline
\end{tabular}

Tabel 17. Normalisasi Sub-kriteria PL terhadap Alternatif

\begin{tabular}{ccccc}
\hline Alternatif & PrivyID & DigiSign & Manual Input & Rata-rata \\
\hline PrivyID & 0,158 & 0,138 & 0,375 & 0,223 \\
DigiSign & 0,789 & 0,690 & 0,500 & 0,660 \\
Manual Input & 0,053 & 0,172 & 0,125 & 0,117 \\
\hline Jumlah & 1 & 1 & 1 & 1
\end{tabular}

6. Matriks perbandingan alternatif sub-kriteria SML

Nilai perbandingan alternatif platform tanda tangan digital berikutnya adalah berdasarkan sub-kriteria sistem manajemen lingkungan, dapat dilihat pada tabel dibawah ini:

Tabel 18. Matriks Perbandingan Alternatif Berdasarkan Sub-kriteria SML

\begin{tabular}{cccc} 
Alternatif & PrivyID & DigiSign & Manual Input \\
\hline DigiSign & 1 & 3 & 3 \\
PrivyID & 0,333 & 1 & 3 \\
Manual Input & 0,333 & 0,333 & 1 \\
\hline Jumlah & 1,666 & 4,333 & 7
\end{tabular}

Tabel 19. Normalisasi Sub-kriteria SML terhadap Alternatif

\begin{tabular}{ccccc}
\hline Alternatif & PrivyID & DigiSign & Manual Input & Rata-rata \\
\hline PrivyID & 0,600 & 0,692 & 0,429 & 0,574 \\
DigiSign & 0,200 & 0,231 & 0,429 & 0,286 \\
Manual Input & 0,200 & 0,077 & 0,142 & 0,140 \\
\hline Jumlah & 1 & 1 & 1 & 1
\end{tabular}

7. Matriks perbandingan alternatif sub-kriteria CS

Nilai perbandingan alternatif platform tanda tangan digital berikutnya adalah berdasarkan sub-kriteria customer service, dapat dilihat pada tabel dibawah ini:

Tabel 20. Matriks Perbandingan Alternatif Berdasarkan Sub-kriteria CS

\begin{tabular}{cccc}
\hline Alternatif & PrivyID & DigiSign & Manual Input \\
\hline PrivyID & 1 & 3 & 5 \\
DigiSign & 0,333 & 1 & 3 \\
Manual Input & 0,2 & 0,333 & 1 \\
Jumlah & 1,533 & 4,333 & 9
\end{tabular}

Tabel 21. Normalisasi Sub-kriteria CS terhadap Alternatif

\begin{tabular}{ccccc}
\hline Alternatif & PrivyID & DigiSign & Manual Input & Rata-rata \\
\hline PrivyID & 0,652 & 0,692 & 0,556 & 0,633 \\
DigiSign & 0,217 & 0,231 & 0,333 & 0,261 \\
Manual Input & 0,131 & 0,077 & 0,111 & 0,106 \\
\hline Jumlah & 1 & 1 & 1 & 1
\end{tabular}

8. Matriks perbandingan alternatif sub-kriteria KD

Nilai perbandingan alternatif platform tanda tangan digital berikutnya adalah berdasarkan sub-kriteria keamanan data pengguna. Berikut ini adalah matriks perbandingan alternatif yang dapat dilihat pada tabel dibawah ini:

Tabel 22. Matriks Perbandingan Alternatif Berdasarkan Sub-kriteria KD

\begin{tabular}{cccc}
\hline Alternatif & PrivyID & DigiSign & Manual Input \\
\hline PrivyID & 1 & 0,2 & 4 \\
DigiSign & 5 & 1 & 5
\end{tabular}




\begin{tabular}{cccc} 
Manual Input & 0,250 & 0,2 & 1 \\
\hline Jumlah & 6,250 & 1,400 & 10 \\
\hline
\end{tabular}

Tabel 23. Normalisasi Sub-kriteria KD terhadap Alternatif

\begin{tabular}{ccccc}
\hline Alternatif & PrivyID & DigiSign & Manual Input & Rata-rata \\
\hline PrivyID & 0,160 & 0,143 & 0,400 & 0,234 \\
DigiSign & 0,800 & 0,714 & 0,500 & 0,672 \\
Manual Input & 0,040 & 0,143 & 0,100 & 0,094 \\
\hline Jumlah & 1 & 1 & 1 & 1
\end{tabular}

9. Matriks perbandingan alternatif sub-kriteria KK

Nilai perbandingan alternatif platform tanda tangan digital berikutnya adalah berdasarkan sub-kriteria kemudahan komunikasi. Berikut ini adalah matriks perbandingan alternatif yang dapat dilihat pada tabel dibawah ini:

Tabel 24. Matriks Perbandingan Alternatif Berdasarkan Sub-kriteria KK

\begin{tabular}{cccc}
\hline Alternatif & PrivyID & DigiSign & Manual Input \\
\hline PrivyID & 1 & 0,333 & 3 \\
DigiSign & 3 & 1 & 4 \\
Manual Input & 0,333 & 0,25 & 1 \\
\hline Jumlah & 4,333 & 1,583 & 8
\end{tabular}

Tabel 25. Normalisasi Sub-kriteria KK terhadap Alternatif

\begin{tabular}{ccccc}
\hline Alternatif & PrivyID & DigiSign & Manual Input & Rata-rata \\
\hline PrivyID & 0,231 & 0,210 & 0,375 & 0,272 \\
DigiSign & 0,692 & 0,632 & 0,500 & 0,608 \\
Manual Input & 0,077 & 0,158 & 0,125 & 0,120 \\
\hline Jumlah & 1 & 1 & 1 & 1 \\
\hline
\end{tabular}

Setelah selesai melakukan perhitungan sintesis matriks perbandingan dan normalisasi pada setiap sub-kriteria sustainability diatas, tahap berikutnya adalah pengambilan keputusan (decision making) untuk menentukan platform tanda tangan digital mana yang lebih baik dibandingkan platform lainnya berdasarkan hasil rata-rata dari setiap sub-kriteria dibagi dengan nilai rata-rata prioritas, hasil perhitungannya adalah sebagai berikut:

Tabel 26. Perhitungan Pengambilan Keputusan terhadap Alternatif

\begin{tabular}{cccccccccc}
\hline Alternatif & IP & KS & CI & KE & PL & SML & CS & KD & KK \\
\hline Bobot Prioritas & 0,081 & 0,174 & 0,257 & 0,107 & 0,060 & 0,037 & 0,099 & 0,150 & 0,036 \\
\hline PrivyID & 0,303 & 0,607 & 0,258 & 0,286 & 0,223 & 0,574 & 0,633 & 0,234 & 0,272 \\
\hline DigiSign & 0,607 & 0,303 & 0,603 & 0,140 & 0,660 & 0,286 & 0,261 & 0,672 & 0,608 \\
\hline Manual Input & 0,090 & 0,090 & 0,139 & 0,574 & 0,117 & 0,140 & 0,106 & 0,094 & 0,120 \\
\hline
\end{tabular}




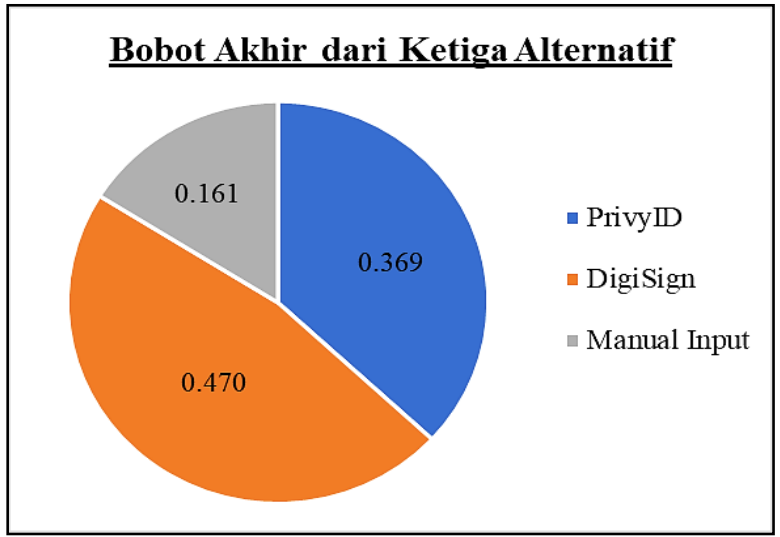

Gambar 2. Grafik Bobot Akhir dari Ketiga Alternatif

Berdasarkan hasil perhitungan pengambilan keputusan terhadap tiga alternatif diatas, diperoleh platform DigiSign yang paling tinggi dengan nilai bobot akhir adalah 0,470, dimana bobot tersebut merupakan bobot paling tinggi dibandingkan dengan sistem atau metode lainnya. Hasil penelitian ini sejalan dengan penelitian yang dilakukan oleh Chong et al. [13], dimana faktor karakteristik ekonomi menjadi faktor prioritas dan dominan terhadap minat pelanggan untuk menggunakan sistem tanda tangan digital

\section{Kesimpulan}

Berdasarkan hasil yang diperoleh dalam penelitian ini menunjukkan bahwa sub-kriteria continuous improvement (CI) yang merupakan sub-kriteria dari dimensi ekonomi menjadi prioritas utama dalam mengembangkan sistem tanda tangan digital secara keseluruhan dengan jumlah persentase sebesar $25,7 \%$. Selanjutnya, hasil perhitungan terhadap tiga alternatif yang telah dilakukan berdasarkan masing-masing sub-kriteria menunjukkan bahwa platform DigiSign berada pada rangking pertama dengan nilai bobot akhir adalah 0,470. Hasil ini sejalan dengan komitmen dari platform DigiSign yang dikutip dari situs resmi digisign.id menjelaskan bahwa DigiSign memberikan kemudahan bagi para pengguna agar dapat memeriksa dokumen yang tertunda dengan cepat, menandatangani dokumen secara aman dengan enkripsi berstandar Internasional, serta dapat melacak status dokumen dengan mudah.

Penelitian ini memiliki keterbatasan terutama dalam hal analisis faktor-faktor perilaku sosial yang belum dibahas secara mendalam terhadap pengadopsian tanda tangan digital. Oleh karena itu, penelitian selanjutnya diharapkan dapat melakukan analisis perilaku sosial (human behavior) yang mempengaruhi minat pelanggan pada suatu institusi atau instansi perusahaan yang lebih spesifik (misalnya perbankan, industri manufaktur dan non-manufaktur, lembaga pemerintahan, dan lainnya) untuk menggunakan tanda tangan digital melalui teori technologyorganization-environment (TOE), unified theory of acceptance and use of technology (UTAUT), technology acceptance model (TAM) atau penggabungan dari teori-teori tersebut untuk memperoleh hasil penelitian yang valid dan akurat dalam menganalisis perilaku sosial terhadap pengadopsian tanda tangan digital di Indonesia.

\section{Daftar Pustaka}

[1] A. Alshehhi, H. Nobanee, and N. Khare, "The impact of sustainability practices on corporate financial performance: Literature trends and future research potential," Sustainability (Switzerland), vol. 10, no. 2. 2018, doi: 10.3390/su10020494.

[2] S. Aksin-Sivrikaya and C. B. Bhattacharya, "Where Digitalization Meets Sustainability: Opportunities and Challenges," 2017.

[3] F. F. Khizbullin, T. G. Sologub, S. V. Bulganina, T. E. Lebedeva, V. S. Novikov, and V. V. Prokhorova, "The direction of transformation of Information and Communication Technology (ICT) at the present stage of development into an electronic and information 
society," Pertanika J. Soc. Sci. Humanit., vol. 25, no. 8, pp. 45-58, 2017.

[4] BSSN, "Laporan Hasil Monitoring Keamanan Siber Tahun 2020," Pusat Operasi Keamanan Siber Nasional, pp. 10-13, 2020.

[5] I. Abdullah, "COVID-19: Threat and Fear in Indonesia," Am. Psychol. Assoc., pp. 488490, 2020.

[6] A. Antoni, "Kejahatan Dunia Maya (Cyber Crime) Dalam SIMAK Online," Nurani J. Kaji. Syari'ah dan Masy., vol. 17, no. 2, 2018, doi: 10.19109/nurani.v17i2.1192.

[7] D. Iskandar and Istaningsih, "The effect of safety, easy and promotion on the behavior of food e-commerce use system in the COVID-19 pandemic time," Int. J. Manag. Stud. Soc. Sci. Res., vol. 3, no. 3, pp. 352-371, 2021.

[8] Bank Indonesia, "Laporan Akuntabilitas Tahunan Bank Indonesia 2020," Laporan Tahunan Bank Indonesia, 2020.

[9] A. I. Dzhangarov and M. A. Suleymanova, "Electronic digital signature," in IOP Conference Series: Materials Science and Engineering, 2020, vol. 862, no. 5, doi: 10.1088/1757-899X/862/5/052054.

[10] A. A. Nugroho, A. Winanti, and A. Surahmad, "Personal Data Protection in Indonesia: Legal Perspective," Int. J. Multicult. Multireligious Underst., vol. 7, no. 7, pp. 183-189, 2020.

[11] M. Yusup, D. Cahvadi, E. Febriyanto, Mardiana, and F. Budiarty, "The Impact of SocioEconomic in Digital Signature Using Blockchain Application," 2020, doi: 10.1109/CITSM50537.2020.9268893.

[12] R. Dermawan, "Pemanfaatan Tanda Tangan Digital Tersertifikasi di Era Pandemi," Rewang Rencang J. Huk. Lex Gen., vol. 2, no. 8, pp. 762-781, 2021.

[13] K. W. Chong, Y. S. Kim, and J. Choi, "A study of factors affecting intention to adopt a cloud-based digital signature service," Inf., vol. 12, no. 2, 2021, doi: 10.3390/info12020060.

[14] L. Costaner, G. Guntoro, and F. Alfarasy, "Analisis Analitical Hierarchy Process Dalam Percepat Penyeleksian Penerimaan Tenaga Pendidik," Digit. Zo. J. Teknol. Inf. dan Komun., vol. 12, no. 1, 2021, doi: 10.31849/digitalzone.v12i1.6614.

[15] I. Fahmi, F. Kurnia, and G. E. . Mige, "Perancangan Sistem Promosi Jabatan Menggunakan Kombinasi Analytical Hierarchy Process (AHP) dan Profile Matching (PM)," J. SPEKTRO, vol. 2, no. 1, 2019.

[16] A. Mauko, M. B, and P. Sugiartawan, "Sistem Pendukung Keputusan Kelompok pemilihan Saham LQ45 dengan menggunakan metode AHP, Promethee dan BORDA," J. Sist. Inf. dan Komput. Terap. Indones., vol. 1, no. 1, 2018, doi: 10.33173/jsikti.6.

[17] P. Diah, S. Dewi, and S. Suryati, "Penerapan Metode AHP dan SAW untuk Penentuan Kenaikan Jabatan Karyawan," JATISI (Jurnal Tek. Inform. dan Sist. Informasi), vol. 5, no. 1, 2018, doi: 10.35957/jatisi.v5i1.130.

[18] R. Rachman, "Penerapan Metode AHP Untuk Menentukan Kualitas Pakaian Jadi Di Industri Garment," J. Inform., vol. 6, no. 1, 2019, doi: 10.31311/ji.v6i1.4389.

[19] A. S. R. Sinaga, "Penentuan Karyawan Lembur Dengan Metode Analytical Hierarchy Process (AHP)," J. Inkofar, vol. 1, no. 2, 2019, doi: 10.46846/jurnalinkofar.v1i2.67.

[20] I. Granita, "Financial Technology Di Indonesia," J. Teknol. Inf., vol. 2, no. 1, 2020.

[21] A. F. Kresna, "Legalitas Tanda Tangan Elektronik Pejabat Dalam Rangka Mendukung E-Government," Humas Mahkamah Agung Republik Indonesia, 2019.

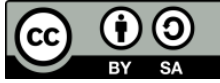

